\title{
Second order motion compensated spin echo cardiac diffusion tensor imaging on clinical MR systems
}

\author{
Christian T Stoeck ${ }^{1,2^{*}}$, Constantin von Deuster ${ }^{2,1}$, Sebastian Kozerke ${ }^{1,2}$ \\ From 19th Annual SCMR Scientific Sessions \\ Los Angeles, CA, USA. 27-30 January 2016
}

\section{Background}

Recently second order motion compensated spin echo (SE) sequences in conjunction with high performance gradient systems have been proposed for diffusion weighted (DWI) [1] and diffusion tensor imaging (DTI) $[2,3]$ of the human in vivo heart. The method allows for free breathing acquisition without requiring dedicated patient feedback systems or other provisions [4], facilitating the transition of cardiac DTI into a clinical environment.

In this preliminary study we investigate the limits of SE based cardiac DTI relative to available gradient strengths to explore the required gradient specifications of clinical MR equipment.

\section{Methods}

Cardiac DTI was acquired on three healthy volunteers $(28 \pm 4$ years $/ 67 \pm 11 \mathrm{~kg})$ on a $1.5 \mathrm{~T}$ clinical system (Philips Healthcare, Best, The Netherlands) equipped with a 5-channel cardiac receiver coil and a high performance gradient system $\left(G_{\max } 80 \mathrm{mT} / \mathrm{m}\right.$, slew rate $100 \mathrm{mT} / \mathrm{m} / \mathrm{ms})$. The imaging sequence consists of a second order motion compensated SE imaging module with a single shot EPI readout [2]. The sequence parameters are: FOV $230 \times 100 \mathrm{~mm}^{2}$, resolution $2.5 \times 2.5 \mathrm{~mm}^{2}$, slice thickness $6 \mathrm{~mm}, 10$ averages, TR 3R-R. Three slices (apex $/ \mathrm{mid} /$ base) were acquired triggered to $50 \%$ systole during free breathing and navigator gating (gating window $7 \mathrm{~mm}$ ). $\mathrm{G}_{\max }$ per channel was set to $30,40,60$ and $80 \mathrm{mT} / \mathrm{m}$ resulting in a TE of $96,85,73$ and $66 \mathrm{~ms}$. Three orthogonal diffusion encoding directions with $\mathrm{b}=$ $100 \mathrm{~s} / \mathrm{mm}^{2}$ and 9 directions with $\mathrm{b}=450 \mathrm{~s} / \mathrm{mm}^{2}$ were

\footnotetext{
IInstitute for Biomedical Engineering, University and ETH Zurich, Zurich, Switzerland

Full list of author information is available at the end of the article
}

acquired. The orientation of the directions was optimized to generate effective gradient strengths of $43,56,84$ and $105 \mathrm{mT} / \mathrm{m}$.

The LV was manually segmented and helix as well as transverse angles [5] were estimated. For a sector wise comparison the LV was segmented according to the AHA sectors with 5 transmural layers. To estimate the influence of low SNR due to prolonged TE, angulation was estimated additionally using only 4 out of 10 averages acquired at $\mathrm{G}_{\max }=80 \mathrm{mT} / \mathrm{m}$.

\section{Results}

Figure 1a) shows example helix angle maps at midventricular level and the corresponding transmural helix angle histograms. Image quality was found to be comparable for $G_{\max }$ as low as $40 \mathrm{mT} / \mathrm{m}$. Figure $1 \mathrm{~b}$ ) shows the sector wise comparison based on singed mean difference and root-mean-squared errors (RMSE). Figure 2 presents the corresponding analysis for the transverse angle. Large transverse angle are predominantly found at the border of the myocardium and in the vicinity of the posterior vein. The average RMSE was below $12^{\circ}$ over all slices for helix and transverse angles for $G_{\max }$ as low as $40 \mathrm{mT} / \mathrm{m}$. No trend is visible from the signed mean differences indicting a potential bias. The increased patchiness of the angle maps found with lower $G_{\max }$ is attributed to reduced SNR.

\section{Conclusions}

This study indicates that second order motion compensated spin echo diffusion tensor imaging is feasible on clinical MR systems without dedicated high performance gradients. 


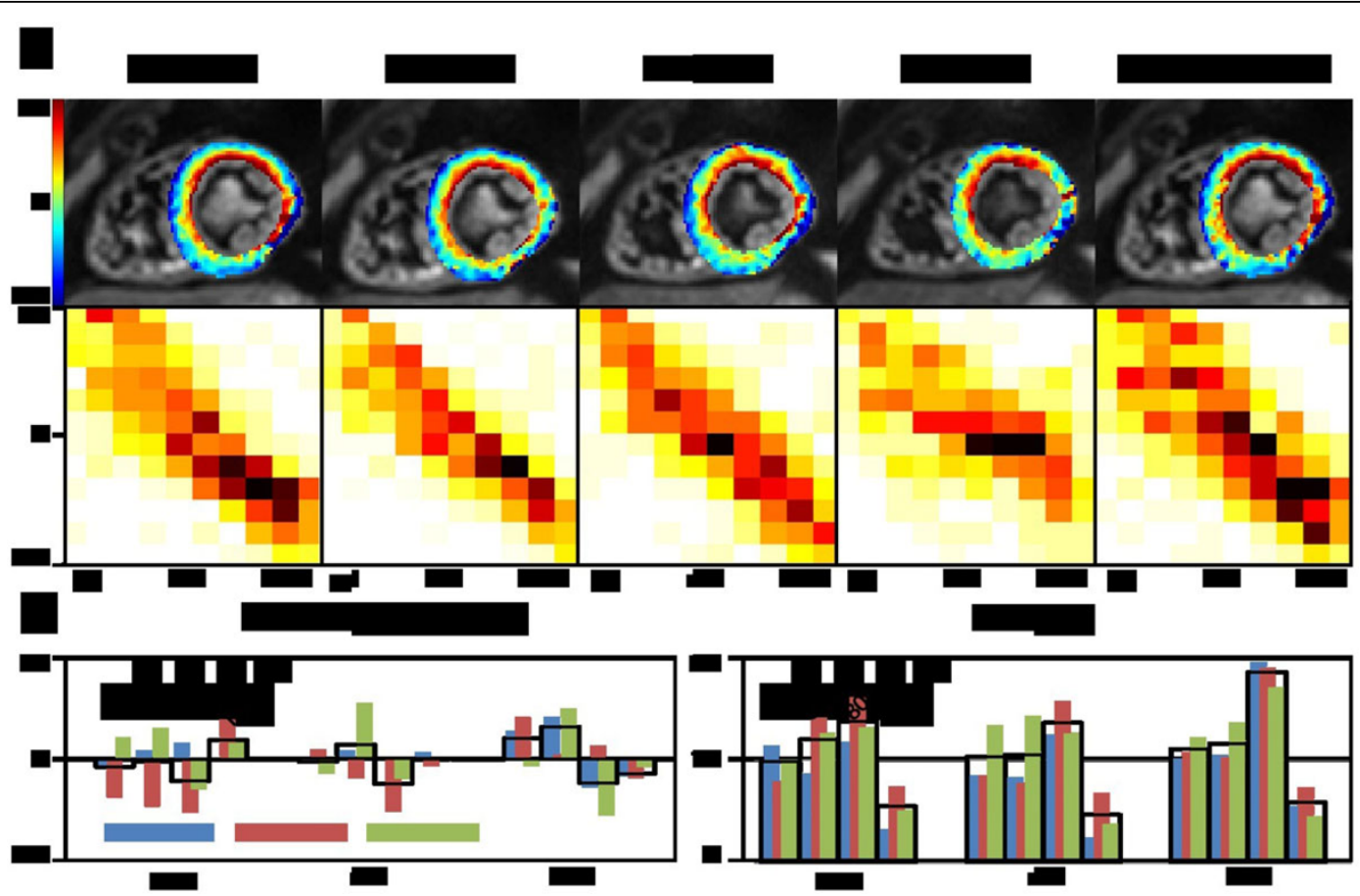

Figure 1 a) Helix angle maps and transmural helix angle histograms of a midventricular slice. $G_{\max }$ per channel is varied from $30 \mathrm{mT} / \mathrm{m}$ to $80 \mathrm{mT} / \mathrm{m}$. Data reconstructed from only 4 signal averages at Gmax $=80 \mathrm{mT} / \mathrm{m}$ mimicking reduced SNR of the low $G_{\max }$ acquisition is shown in the right column. b) Signed mean differences and RMSE for a sector wise analysis at apical, midventricular and basal level. The black boxes indicate the average over all sectors.

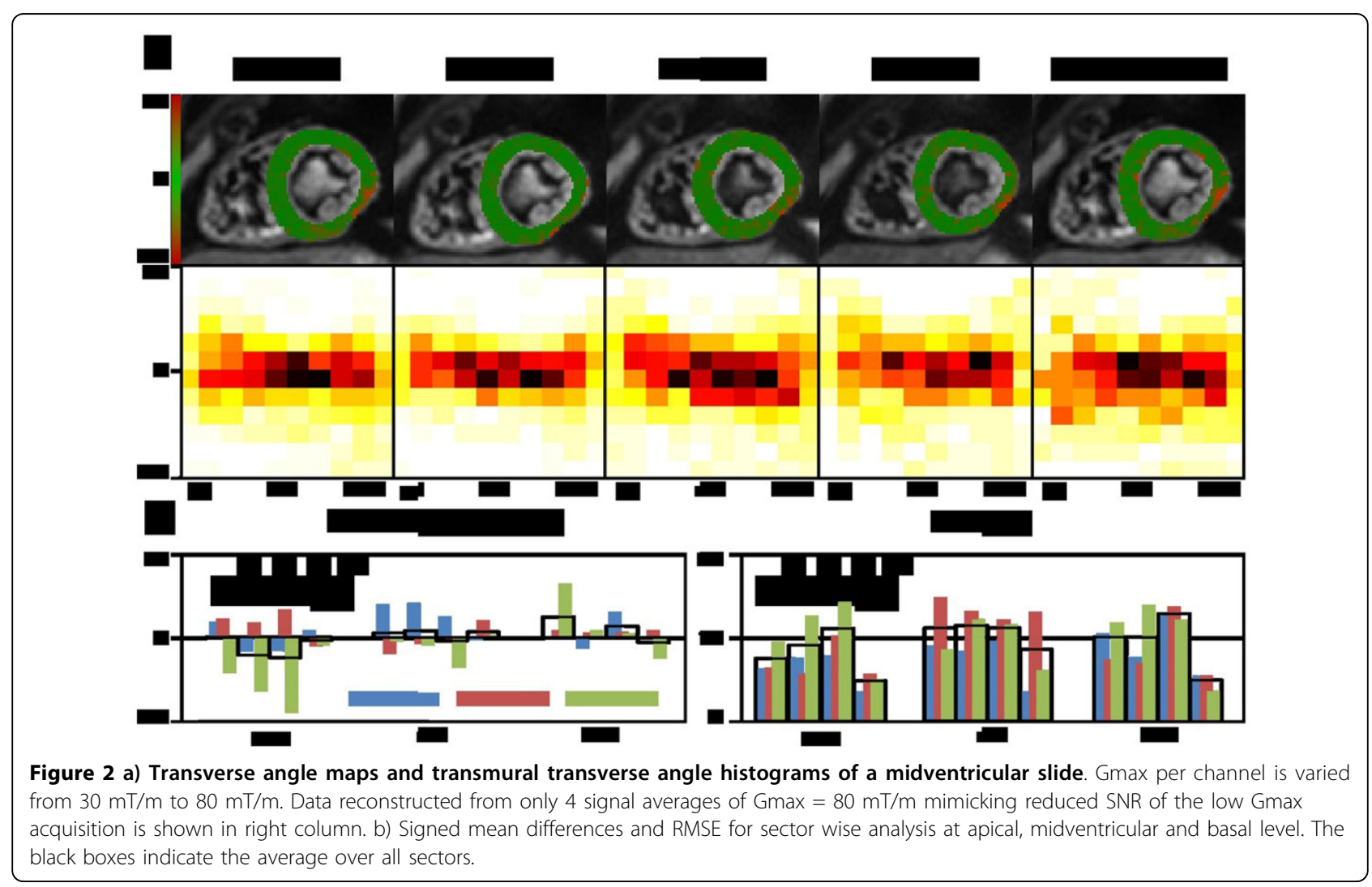




\section{Authors' details}

'Institute for Biomedical Engineering, University and ETH Zurich, Zurich,

Switzerland. ${ }^{2}$ Imaging Sciences and Biomedical Engineering, King's College

London, London, UK.

Published: 27 January 2016

\section{References}

1. Nguyen: MRM 2013.

2. Stoeck: MRM 2015

3. Froeling: SCMR 2015.

4. Nielles-Vallespin: MRM 2013

5. Scollan: AJP 1998.

\section{doi:10.1186/1532-429X-18-S1-P61}

Cite this article as: Stoeck et al:: Second order motion compensated spin echo cardiac diffusion tensor imaging on clinical MR systems. Journal of Cardiovascular Magnetic Resonance 2016 18(Suppl 1):P61.

Submit your next manuscript to BioMed Central and take full advantage of:

- Convenient online submission

- Thorough peer review

- No space constraints or color figure charges

- Immediate publication on acceptance

- Inclusion in PubMed, CAS, Scopus and Google Scholar

- Research which is freely available for redistribution

Submit your manuscript at www.biomedcentral.com/submit
C Biomed Central 